\title{
IDEOLOGIA E DOMINAÇÃO NO BRASIL (1974- 1989): um estudo sobre a Escola Superior de Guerra
}

\author{
Everton Rodrigo Santos*
}

Resumo: Este artigo analisa as formas de produção simbólica efetuadas na Escola Superior de Guerra (ESG) e suas relações com o quadro de dominação assimétrico entre civis e militares no Brasil. A hipótese que o orienta o trabalho é de que a ESG constitui-se num lócus de produção de formas simbólicas de tipo ideológica, ou seja, de que os sentidos mobilizados por esta instituição no período em análise, no quadro da transição para a democracia no Brasil (1974/1989), serviram naquelas circunstâncias sócio-históricas específicas para sustentar relações de dominação assimétricas duráveis entre civis e militares, cristalizando desta forma o seu caráter ideológico. Para tanto, utilizamos a proposta teórico-metodológica de Thompson (1995) em sua Hermenêutica de Profundidade (HP), aliada à análise de conteúdo de Bardin (1977).

Palavras-chave: ideologia, dominação, Escola Superior de Guerra.

\section{Introdução}

Em agosto de 1949 é fundada, na cidade do Rio de Janeiro, então capital federal da República brasileira, a Escola Superior de Guerra (ESG). Esta escola, como um "centro misto de estudos

\footnotetext{
* Doutor em Ciência Política pela UFRGS; professor titular no Centro Universitário FEEVALE, onde atua como pesquisador no Grupo de Estudos em Desenvolvimento Regional; professor adjunto na ULBRA no ensino de Graduação e no Programa de PósGraduação em Ciência Política e Odontologia. E-mail: evertons@feevale.br

Este artigo é parte de um capítulo da tese de Doutorado em Ciência Política, defendida pelo autor, em 2005, na UFRGS sob o título Ideologia e dominação no quadro da transição democrática no Brasil (1974/1989): um estudo sobre a Escola Superior de Guerra.
}

Artigo recebido em 14 set. 2006 e aprovado em 4 abr 2007. 
militares e civis", onde se elaboravam alternativas aos obstáculos do desenvolvimento nacional no contexto político do pós-guerra, tinha em sua localização geográfica na capital muito mais do que uma coincidência, um desejo manifesto de influir nos rumos da política nacional. De fato, na seqüência histórica, a ruptura institucional de 1964 reservou à ESG um importante papel, pois, a partir de suas formulações doutrinárias, foi possível a um grupo de militares e civis não somente elaborar um projeto político para o país, que articulasse de forma coerente segurança com desenvolvimento econômico, como também catapultar muitos dos seus quadros à estrutura estatal "pós-revolução", o que ficou cristalizado na ascendência do general Castelo Branco à Presidência da República. Ele mesmo um esguiano.

Portanto, a história da ESG coloca-a em estreita ligação com os destinos da política nacional. Entretanto, uma importante bibliografia elaborada sobre essa instituição, em décadas pretéritas, parece ter ficado ou aquém ou além de uma importante especificidade desta instituição no quadro da política nacional. Das análises que apresentam a ESG e sua ideologia como um instrumento a serviço da modernização do capitalismo, até as análises marxistas/ gramscianas que a colocam a serviço das "classes economicamente dominantes", em todas elas, a dimensão que mais interessa à análise política e ao futuro da democracia, a saber, as relações de poder aí estabelecidas entre civis e militares, têm sido, senão negligenciadas, tangencialmente tocadas. ${ }^{1}$

Desta forma, interessa-nos, particularmente, o estudo da produção simbólica efetuadas na ESG entre os anos de 1974 a 1989 correspondentes ao governo do General Ernesto Geisel estendendose ao governo do presidente José Sarney. 
Esta análise busca testar a hipótese, a partir do conceito de ideologia em Thompson (1995), de que a Escola Superior de Guerra (ESG) constitui-se num lócus de produção de formas simbólicas de tipo ideológico. Ou seja, a instituição caracteriza-se como um espaço de mobilização dos sentidos para sustentar relações de dominação civil-militares assimétricas e duráveis, que se cristalizam no período em estudo, constituindo-se, desta forma, como um espaço de resistência ao aperfeiçoamento das relações civil-militares no Brasil e, conseqüentemente, de sustentação do regime político autoritário/ tutelado na transição.

Este artigo terá três eixos básicos sobre os quais construiremos nosso argumento, e, conseqüentemente, a demonstração de nossa hipótese. No primeiro eixo apresentamos uma revisão de parte da bibliografia básica que trata sobre a ESG (e que atende aos objetivos deste trabalho), procurando identificar concepções de ideologia subjacentes e comuns a estes estudos. Ao final do tópico, propomos como recurso de análise, a utilização do conceito de "ideologia crítica" em Thompson (1995). No segundo eixo, fazemos a reconstrução sócio-histórica do período e a análise formal da documentação na ESG (análise de conteúdo temático), para demonstrar como tais documentos produzidos na escola, e recepcionando os aspectos doutrinários da Doutrina de Segurança Nacional (DSN), ${ }^{2}$ sustentam "os militares enquanto governo", e "enquanto instituição". ${ }^{3}$

No terceiro eixo, procuramos demonstrar a defesa da ESG a uma democracia de tipo tutelada durante o governo Sarney, trazendo à superfície do processo político as posições da instituição ESG e suas relações com a estrutura de dominação civil-militar.

Estes três eixos procuram corroborar o respaldo esguiano à defesa da "institucionalização do Estado de Segurança Nacional", sublinhando seu aspecto ideológico. 


\section{Uma proposta analítica contemporânea sobre a ESG}

\section{Ideologia neutra}

Da bibliografia básica que trata sobre a ESG, o trabalho de Stepan (1971) ocupa um lugar importante na literatura, pois teve o mérito de demonstrar, não sem controvérsias, o importante papel dirigista que os militares assumiram a partir da segunda metade do século XX através da sua passagem pela instituição. Para os objetivos deste artigo, o que importa salientar é o uso de seu conceito de ideologia. Em seu trabalho, a ideologia constitui-se num conjunto de idéias e procedimentos para a modernização do país, um projeto político nacional da "Segurança e do Desenvolvimento", inclusivo das demandas dos civis para a nação que levou à ação política dos militares. $^{4}$

Em Aderaldo (1978), numa outra perspectiva metodológica, a ESG tinha claramente um "objetivo instrumental propositivo", de influir nos rumos do governo, propondo políticas para serem implementadas, sublinhando que muitas das idéias gestadas na Escola nos anos 50 e 60 foram incorporadas ao Estado no "pósrevolução, inclinando-se para uma concepção neutra (subjacente) também quanto ao trato da ideologia". Com Miyamoto (1995), novamente aparece o sentido "neutro", quando aborda a questão da ideologia nos estudos geopolíticos da escola. ${ }^{5} \mathrm{O}$ autor entende a ideologia como um conjunto de idéias disseminadas pela ESG, conforme argumenta em seu capítulo segundo, salientando os aspectos que ele chama de "Doutrina e Ideologia".

Nesses estudos, o que há de comum é que não há nenhum aspecto pejorativo no uso do termo ideologia explícito por Stepan (1971; 1986), ou implícito por Aderaldo (1978) e Miyamoto (1995). A ideologia proposta na ESG aparece como um conjunto de idéias, conceitos e valores articulados como qualquer outro, sem 
implicar necessariamente que eles sejam enganadores ou mesmo ilusórios. Estas análises ignoram o caráter assimétrico das relações de dominação que pode carregar DSN, quer sejam econômicas ou políticas. Estas concepções neutras de ideologia não estão preocupadas com aquele aspecto da "denúncia", da ideologia como algo que possa ou que deva ser eliminado.

Desses trabalhos, e guardadas as diferenças entre os autores, podemos tirar três conclusões importantes. Em primeiro lugar, a intervenção dos militares na política se dá como resposta à resolução dos problemas nacionais. Stepan (1971) é mais explícito. Em segundo lugar, a ênfase é colocada no projeto político nacional, uma Doutrina que está a serviço dos interesses nacionais. Assim, os trabalhos de Stepan (1971), (modernização), Miyamoto (1995), (geopolítica), e Aderaldo (1978), ("propositivo"), desembocam na “concepção neutra" de ideologia. A dimensão enfocada é aquela pela qual a ideologia responde às crises do sistema político/econômico, ou seja, a ideologia que responde aos problemas do sistema com idéias e projetos para o País (Figura 1).

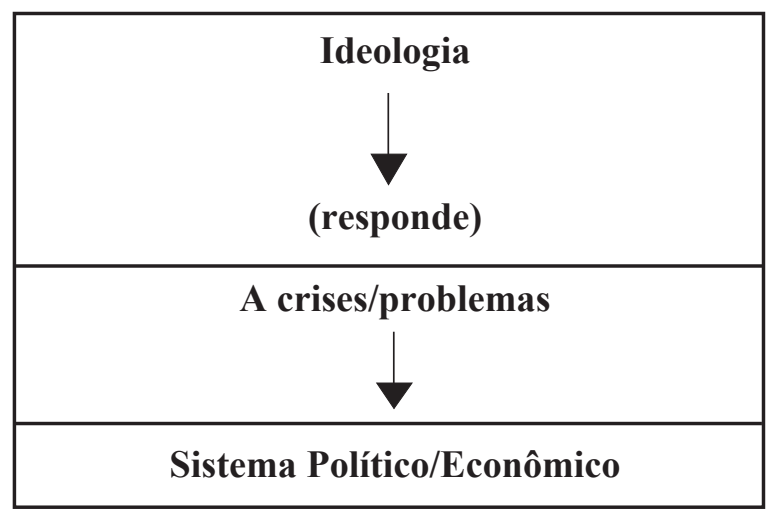

Fonte: do autor

Figura 1 - Ideologia neutra 
Como podemos perceber, os interesses próprios dos militares não aparecem nestas formulações, e, quando aparecem, estão a serviço de outros, no caso dos civis, da modernização etc. Esta é a terceira importante conclusão que tiramos desses estudos (Santos, 2006).

\section{Ideologia negativa}

Diferentemente da perspectiva dos "neutros", que abordam a ideologia como um projeto político modernizador, "propositivo" para o País diante de uma crise política, as análises marxistas/ gramscianas irão reforçar seu caráter "negativo", de um conjunto de idéias que estão aí para uma dominação de classe, indicando que o fenômeno caracterizado como ideologia ou como ideológico é enganador, ilusório ou parcial. A ideologia burguesa ou das "classes dominantes" - para estes autores - é algo que precisa ser superado, o que não era a preocupação dos neutros. ${ }^{6}$

É assim que, na análise de Oliveira (1976), a ideologia aparece como expressão dos interesses culturais das classes dominantes; em Ianni (1985), como a expressão do predomínio da grande "burguesia financeira e monopolista"; ou mesmo em Dreifuss (1981), como instituição que representa e defende os interesses do grande "capital multinacional e seus associados".

Essas formulações acabaram inovando as análises pretéritas, que realçavam a condição "neutra da ideologia". O avanço significativo dessas abordagens foi demonstrar que a DSN articulava interesses e mobilizava os sentidos numa direção determinada - a direção de representantes do capital -, superando as análises até então tradicionais do projeto nacional.

Sendo uma formulação teórica que se dá no contexto bipolar do pós-guerra, suas preocupações são muito mais estruturais, 
econômicas, culturais (dominação burguesa) do que propriamente políticas e militares. A dimensão enfocada é a relação entre ideologia e representação de interesses de classe no Capitalismo (Figura 2). Aqui vemos que a primeira tem uma função de representação em relação a estas.

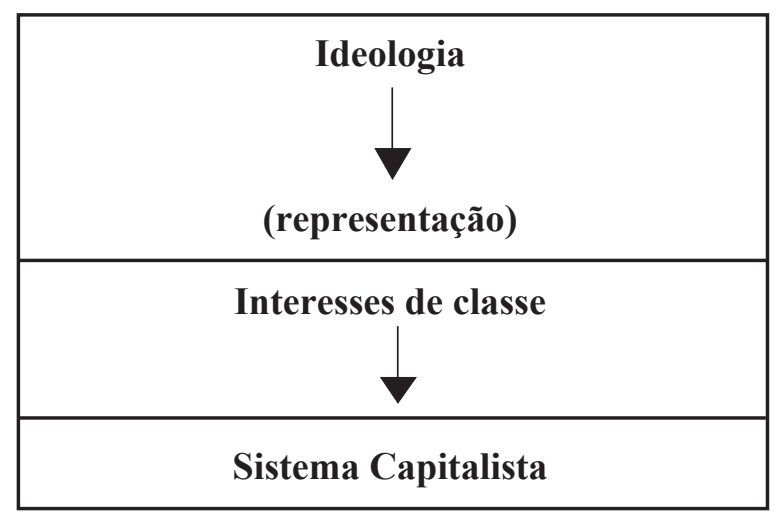

Fonte: do autor

\section{Figura 2 - Ideologia negativa}

Desta forma, o tópico a seguir pretende apresentar uma perspectiva teórica inovadora, para o estudo da ESG, que contemple esta dimensão, a dimensão política.

\section{Ideologia crítica}

Pensamos ser possível fazer avançar a compreensão sobre o fenômeno ideológico presente na ESG, buscando superar tanto a "concepção neutra" quanto a "concepção negativa" das análises tradicionais com forte viés de classe, revitalizando o uso do conceito de ideologia em seu caráter político. Pensamos que a proposta apresentada por Thompson (1995) traz um enfoque original nos estudos sobre ideologia. As formas simbólicas não são ideológicas 
em si mesmas para este autor. Se elas são ideológicas ou não, vai depender das maneiras como são usadas e entendidas em contextos sociais específicos; em outras palavras, se elas servem para estabelecer e sustentar relações de dominação nos contextos sociais em que elas são produzidas, transmitidas e recebidas. Para ele,

a análise da ideologia (...) está primeiramente interessada com as maneiras como as formas simbólicas se entrecruzam com relações de poder. Ela está interessada nas maneiras como o sentido é mobilizado, no mundo social, e serve, por isso, para reforçar pessoas e grupos que ocupam posições de poder. (Thompson, 1995, p. 76).

Então, para Thompson (1995) existem relações de dominação numa dada sociedade, quando relações estabelecidas de poder são "sistematicamente assimétricas", isto é, quando grupos particulares de agentes possuem poder de uma maneira permanente e em grau significativo, permanecendo, desta forma, inacessíveis a outros grupos.

Thompson (1995) não restringe a ideologia às relações de dominação econômica, bem como não reduz esta a um caráter ilusório. Ele vê as formas simbólicas e o sentido, assim mobilizado por elas, como constitutivos da realidade social e que estão envolvidos tanto em estabelecer como em sustentar relações entre pessoas e grupos. ${ }^{7}$ Assim, as formas simbólicas não estão separadas da realidade ou mesmo são reflexos dela, como quer a tradição marxista, porém elas são partes do que é a realidade. Portanto, quando estamos estudando ideologia,

estamos estudando um aspecto da vida social que é tão real como qualquer outro. Pois a vida social é, até certo ponto, um campo de contestação em que a luta se trava tanto através de palavras e símbolos, como pelo uso da força física. Ideologia [...] é uma parte integrante desta luta; é uma característica criativa e constitutiva da vida social que é sustentada e reproduzida, contestada e transformada, através de ações e interações, as quais incluem a troca contínua de formas simbólicas. (Thompson, 1995, p. 19). 
Também Vincent (1992, p. 31) vai na mesma direção, ao afirmar que as “(...) ideologias não estão lado a lado com alguma coisa objetiva ou real, mas são elas que, sutilmente, constituem a realidade". Assim, a ideologia, como parte da vida social, está envolvida em estabelecer a conexão entre sentido e poder, em mobilizar os sentidos para estabelecer ou sustentar relações de poder na sociedade através do uso de alguns modos de operação da ideologia, como a legitimação, a dissimulação, a unificação, a fragmentação e a reificação. Aqui particularmente nos interessam as relações de dominação entre civis e militares que podem ser também sustentadas e/ou estabelecidas pela mobilização destes sentidos efetuadas pela ESG.

Desta forma, nós teríamos na instituição, nesta ordem das coisas, um lócus do próprio poder militar transfigurado como "poder simbólico" na divulgação de sua doutrina a seus estagiários. Um lócus de "poder simbólico", de "construção da realidade" que apresenta em suas formas de recrutamento, por exemplo, uma importante estratégia de divulgação ideológica.

Neste sentido, nossos estudos sobre a ESG têm indicado a existência de alunos detentores daquilo que Bourdieu (2000) chama de "capital político objetivado" (cf. Santos, 2005). Altos funcionários da administração pública, bem como inúmeros parlamentares, freqüentam os cursos da ESG e são futuros "colaboradores" para as lutas no interior do aparelho estatal, não somente para manter o poder militar sobre os civis, mas também para a disputa de valores dos indivíduos e dos conhecimentos que podem dar forma e direção para os negócios do Estado.

Esta Escola declina de suas pretensões “instrumentais propositivas" ligadas à ação de tomar o Estado (conforme os golpes de Estado na América Latina) e passa a assumir o propósito de manter suas conquistas ("prerrogativas militares") no interior do 
Estado brasileiro (Zaverucha, 2000). Neste sentido, o embate se dá na tentativa de conquistar a maior adesão por parte dos cidadãos a seus princípios, pois a conquista destas adesões acaba se convertendo na conquista de espaços sociais privilegiados, bem como de espaços públicos, uma vez que seus estagiários ocupam posições importantes no Estado e na sociedade, pois os que ocupam posições dominantes no espaço social estão também em posições dominantes no campo de produção simbólica, daí o seu recrutamento. ${ }^{9}$

Os sentidos mobilizados dentro de um contexto histórico e social determinado reforçam um regime político quer seja autoritário, quer seja de "democracia tutelada". Assim, o conceito de "ideologia crítica" de Thompson (1995), superando as análises pretéritas, traz a relação entre ideologia e regime político. Uma ideologia que sustenta relações de dominação civil-militar (Figura 3).

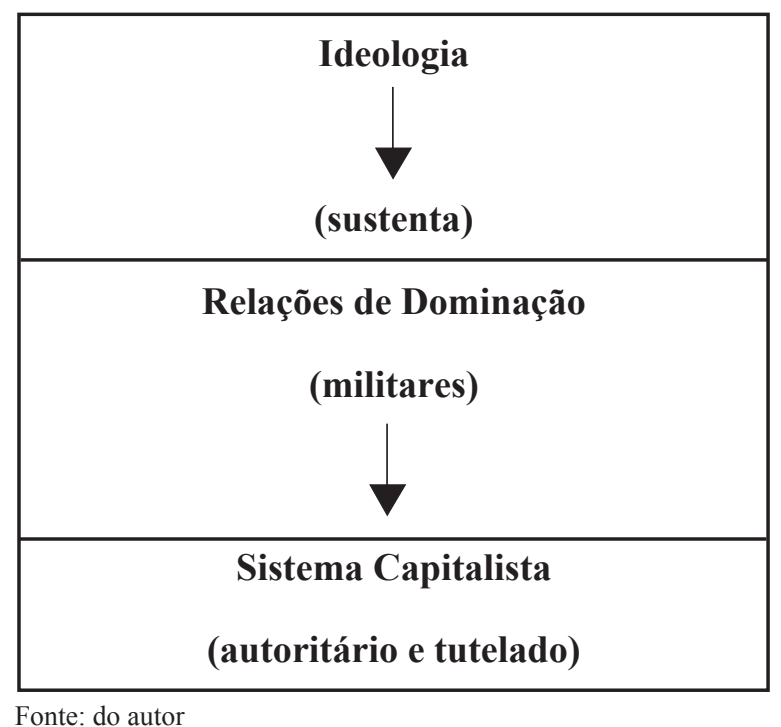

Fonte: do autor

Figura 3 - Ideologia crítica 
Nesta formulação conceitual, podemos sublinhar três aspectos importantes. Primeiro, o conceito reafirma o caráter ideológico da ESG. Em segundo lugar, mas diferentemente das concepções passadas, esta ideologia não está a serviço da dominação burguesa ou de uma modernização capitalista, de um projeto para o país, mas a serviço dos próprios militares (seu estamento). E, finalmente, o conceito nos remete a uma discussão contemporânea sobre as relações de poder recentes entre civis e militares dentro do quadro de um regime político de transição do autoritarismo à democracia.

\section{A sustentação ideológica do regime autoritário na ESG (1974-1984)}

A sustentação ideológica do governo

Se os governos Castelo Branco e Costa e Silva lançaram as bases do Estado de Segurança Nacional corporificado na Constituição autoritária de 1967 e o governo Médici desenvolveu o aparato repressivo e o modelo de desenvolvimento econômico, os governos Geisel e Figueiredo concentraram-se no processo de transição de estruturas mais permanentes e flexíveis para a institucionalização do Estado de Segurança Nacional a longo prazo (Alves, 1984). Traduzindo-se aqui como a garantia dos "militares enquanto governo" e dos "militares enquanto instituição", estas duas dimensões caracterizam as relações de dominação civil-militares, cristalizadas ao longo de todo o processo analisado.

Assim, todos os governos militares, especialmente os dois últimos (Geisel e Figueiredo), trataram de legitimar as sucessões governamentais como uma continuidade da "revolução de 64". Inclusive, o próprio presidente Geisel via seu projeto de distensão como a "institucionalização da revolução". A luta por esta “institucionalização", ou seja, a luta por incorporar à Constituição os 
atos institucionais da "revolução", reforçando relações assimétricas de poder, implicava primeiramente na preservação do grupo de poder no Estado, não se resumindo às suas ações políticas mais objetivas, mas, também, conforme a orientação deste trabalho, através de uma intensa luta simbólica efetuada, entre outras, pela ESG. ${ }^{10} \mathrm{O}$ que ocorria na ESG era a sustentação ideológica desses governos em particular (Geisel e Figueiredo) e do regime autoritário no sentido mais amplo. Ou, como coloca Rezende (2001), a ESG era articuladora da estratégia psicossocial do regime, visava agir sobre a mentalidade dos cidadãos (ou de certos cidadãos), buscando fazer com que estes internalizassem valores e idéias que norteariam suas ações ao lado das suas demais estratégias, política, militar e econômica.

A partir da análise e sistematização dos trabalhos elaborados pelos alunos ao longo dos governos Geisel e Figueiredo, podemos observar como o caráter ideológico da instituição opera de forma eficiente em seus estagiários.

Esse caráter ideológico pode manifestar-se através de quatro modos de operação acompanhadas de estratégias ideológicas, como: 1) a dissimulação (eufemização); 2) a legitimação (universalismo, racionalização e narrativização); 3) a reificação (eternalização); e, 4) a fragmentação (diferenciação e expurgo).

Assim, sabemos que, por meio do modo de operação ideológico da dissimulação, por exemplo, relações de dominação, podem ser estabelecidas e sustentadas pelo simples fato de serem ocultadas, negadas ou suavizadas (Thompson, 1995). Neste sentido, na conjuntura da transição política em curso a partir de 1947, os trabalhos escritos que analisam a ruptura institucional de 1964 demonstram claramente a intenção de suavizar este fato político, dando-lhe um valor positivo e, portanto, obscurecendo-o. Então, através da estratégia simbólica da eufemização (dentro do modo 
ideológico da dissimulação), a ruptura institucional de 1964 é apresentada como "revolução" nas palavras de um estagiário no governo Geisel:

A Revolução de 31 de março de 1964, sem dúvida alguma foi um dos mais importantes acontecimentos de nossa história nesta metade do século XX, (...) resguardou a ordem e a paz social, ao mesmo tempo em que orientou o comportamento dos políticos que viviam em função dos seus interesses pessoais [...]. (DOC 14, p. 5, 1975) (grifo nosso).

A "revolução", como um significante que incorporava um significado positivo na década de 60/70, é apresentada como redentora e restauradora da "ordem e da paz social". A ruptura institucional que, do ponto de vista político, baniu, prendeu, cassou e torturou importantes lideranças políticas, se transforma em "revolução". A busca da suavização para este acontecimento é notória. Os "revolucionários de 1964", principalmente aqueles ligados ao grupo da ESG são os que agora estão na direção política do Estado, no processo de abertura iniciado com Geisel. O caráter ideológico aqui reside precisamente na incorporação, pelos estagiários, de uma suavização que vai ao encontro da sustentação do grupo de poder, pois minimiza suas possíveis defecções.

Paralelo ao modo de operação ideológica da dissimulação, há o da legitimação, em que relações de dominação podem ser estabelecidas por serem representadas como legítimas e dignas de apoio (Thompson, 1995), portanto, o universalismo aparece como uma estratégia ideológica recorrente. Na legitimação, os interesses particulares das Forças Armadas são colocados como interesses universais, buscando legitimar a ruptura institucional de 1964. É assim que aparece nas discussões internas da instituição, discutindose o seguinte argumento:

A família brasileira através de suas mulheres, fez passeatas públicas de protesto e, por fim, veio a revolução redentora. (DOC. 1, p. 28, d. 80). 
Tudo caminhava para o abismo. O colapso nacional era iminente. O povo começou a sentir e, desse sentir, os rumores chegaram às Forças Armadas. Havia necessidade de uma reação, o que ocorreu em 31 de março de 1964. (DOC. 14, p. 3, d. 75) (grifo nosso).

$\mathrm{O}$ argumento é que as Forças Armadas agiram movidas pelos anseios e interesses da "família brasileira", do "povo", e nunca pelo interesse próprio. Este argumento negligencia o fato de que a luta política numa sociedade se dá entre grupos políticos minoritários, em relação ao conjunto da sociedade, buscando seus interesses para a ocupação do Estado. ${ }^{11}$ Apresentar o particular como se fosse universal é uma forma ideológica de sustentar relações de dominação, conforme Thompson (1995).

O governo Geisel, assim como seus antecessores, apesar da repressão, nunca abriu mão dos mecanismos institucionais que lhes dava sustentação e legitimidade. O governo fazia isso, buscando assegurar maioria para a direção do Estado, no Congresso Nacional, Estados e assembléias visando aprovar as reformas necessárias à sua institucionalização, prorrogando ao máximo a chegada da oposição às instâncias superiores deliberativas do Estado e, concomitantemente, preservando o papel institucional das Forças Armadas.

Essa tentativa de a ESG legitimar ideologicamente o Regime Militar foi chamada pela bibliografia especializada de uma aposta na política de "liberalização" em detrimento de uma política de "democratização".

A Constituição de 1967, por exemplo, cristalizando os atos institucionais AI 1, AI 2, AI 3 e, posteriormente, os demais atos, deu um lastro significativo aos governos Geisel e Figueiredo para sua manutenção no poder, recebe respaldo no interior da ESG por um Trabalho Especial (TE). Nesse TE de 1975, o estagiário sublinha e defende que a Constituição brasileira em seu Artigo 15 assevera a autonomia municipal, pela eleição direta de prefeito, vice-prefeito 
e vereadores realizada simultaneamente em todo o País; todavia somente seriam nomeados pelo governador, com prévia aprovação da Assembléia Legislativa, os prefeitos das capitais dos Estados, dos municípios considerados estâncias hidrominerais em lei estadual,e dos municípios declarados de interesse da segurança nacional por lei de iniciativa do Poder Executivo e conclui:

Assim, como vemos, há municípios cujos dirigentes principais são escolhidos por caminhos estranhos ao sistema nacional. E para esses casos não poderia haver outra alternativa. Não tem sentido um Governador de Estado ter na capital de seu Estado um chefe de executivo municipal que lhe traga problemas.

E para os municípios classificados como de segurança nacional e as estâncias hidrominerais, pelos papéis que representam no contexto da própria segurança, dispensam maiores comentários. (DOC.2, p.16/17 d, 1975) (grifo nosso).

$\mathrm{O}$ autor desse texto está se referindo ao $\mathrm{AI} 3$, incorporado à Constituição, que assegurava, entre outras coisas, que os prefeitos das capitais dos Estados seriam nomeados pelos próprios governadores, bem como aqueles prefeitos que fossem de cidades consideradas de segurança nacional. O trecho do documento está dentro do modo de operação da reificação, que sublinha o fato de que relações de dominação podem ser sustentadas pela retratação de uma situação transitória, como se fosse permanente, inevitável (Thompson, 1995), e articula a estratégia da internalizarão, ou seja, ele esvazia o caráter sócio-histórico da formulação do governo (as razões políticas que o levaram a formular tal projeto) e apresenta-o como algo natural, inevitável, "não poderia haver outra alternativa", “dispensam maiores comentários". Um claro exercício de engenharia política para evitar o acesso oposicionista às instâncias superiores deliberativas do Estado é respaldado simbolicamente na ESG. 
A ESG equacionava os problemas do país, através da DSN, preservava os espaços institucionais do governo, mas, fundamentalmente, como veremos a seguir, também sustentava os militares ideologicamente.

\section{A sustentação ideológica dos militares}

Tanto a Constituição de 1967, já mencionada, como a Emenda Constitucional de 1969 mantiveram praticamente intacto o papel das Forças Armadas para o período Geisel e Figueiredo. ${ }^{12} \mathrm{Na}$ emenda de 1969, observamos praticamente a mesma designação, apenas com uma pequena alteração. Nesta, além de garantir "os poderes constitucionais e a lei e a ordem", é dada ênfase ao fato de que as Forças Armadas são "essenciais à política de segurança nacional". $\mathrm{O}$ fato de as Forças Armadas serem colocadas como "essenciais à política de segurança nacional" deve ser visto num contexto em que o combate ao inimigo interno é parte substancial da política dos governos militares, ainda mantido na transição como um "combate perseverante, rigoroso, mas sem excessos".

Esse inimigo interno das Forças Armadas era plenamente identificado na ESG, como vemos:

Desta posição de incontestável superioridade estratégica, o comunismo internacional partiu para a agressão mundial. Esta agressão tem como alvo principal a destruição da cultura e da civilização ocidental (...).

Se hoje o comunismo internacional e o anarquismo estão às portas de nossas cidadelas, urge que nos levantemos contra eles. (DOC.11, p. 23/28, 1975) (grifo nosso).

Observamos neste documento como as recepções simbólicas na identificação dos "inimigos" a serem combatidos é perfeita com a DSN, que identificava o comunismo como inimigo da pátria. $\mathrm{Na}$ 
verdade, através das estratégias simbólicas da diferenciação e do expurgo, chega-se ao modo de operação da fragmentação, ou seja, as relações de dominação podem ser sustentadas pela separação dos amigos e dos inimigos, dos puros e dos impuros. Aqui, por estarmos ainda no quadro da guerra fria, o inimigo a ser combatido é o "comunismo" e o "anarquismo".

Como argumenta Thompson (1995), relações de dominação podem ser mantidas pela segmentação de grupos que possam ser capazes de se transformar em um desafio real aos grupos dominantes. Assim o regime procurava diferenciar aqueles opositores potenciais, desqualificando-os.

A própria edificação do Estado de Segurança Nacional justificou-se pela permanência de um inimigo, daí serem mantidas na Constituição as estruturas de poder dentro das quais estão as Forças Armadas na "garantia dos poderes constituídos, da lei e da ordem". Este papel de tutela que os militares assumem perante a sociedade é perfeitamente sustentado internamente na ESG:

Diante dos antagonismos internos, passaram as Forças Armadas, e em particular o Exército, a constituírem-se em "instrumentos de repressão" à disposição do Estado, de forma a garantir as instituições e a manutenção da ordem. (DOC. 7, p. 28, d. 80) (grifo nosso).

Neste processo, vemos que a ESG, juntamente com o governo, era incapaz de lidar com aquilo que Przeworski (1984, p. 37/38) chamou de "incerteza institucionalizada", ou seja, dos atores envolvidos numa disputa política nenhum ex-ante ou ex-post possui a capacidade de controlar os resultados do jogo: "O poder, transferido de um grupo de pessoas, para um conjunto de regras". ${ }^{13}$ Ocorre que a concepção esguiana acerca da sociedade sempre coloca esta sociedade numa posição de tutela, dependente de "particulares", no caso em questão das Forças Armadas, cujo chamamento à participação, nestas circunstâncias, só pode ser a contemplação 
da política, a aprovação dos projetos do governo. A ESG precisa fazer com que as idéias dos cidadãos também coincidam com as idéias do Estado, o que O'Donnell (1986) chamou de “estatização de significantes", ou seja, o "engessamento" da sociedade pelo Estado. É precisamente nesse "engessamento" que temos seu caráter ideológico revelado.

No tópico subseqüente demonstraremos a continuidade dessa luta política simbólica na ESG pela sustentação das relações de dominação civil-militar que os governos militares mantiveram.

\section{Sustentação ideológica da democracia tutelada na ESG (1985-1989)}

\section{Avalisando a tutela}

Toda a virtude acionada pelos atores políticos envolvidos no processo da transição democrática para a eleição de Tancredo Neves no colégio eleitoral seria atropelada pela fortuna que surpreendentemente acometeu o então presidente eleito de uma enfermidade grave (tumor benigno, leiomioma). A morte do presidente eleito, na seqüência dos acontecimentos, levou ao Palácio do Planalto um dos mais importantes políticos civis do grupo de apoio do regime militar, José Ribamar Sarney, com o apoio da Aliança Democrática.

Desde os primeiros movimentos do governo, a Aliança Democrática já havia assumido compromissos inarredáveis com os militares, como a preservação da destinação constitucional que garantia ao aparelho militar o direito de intervir na ordem interna, preservação das Forças Armadas quanto à doutrina militar da segurança nacional e o não julgamento das Forças Armadas por seu envolvimento e responsabilidades na repressão política durante o regime autoritário (Oliveira, 1994). 
O processo de "transição pelo alto", que ajudou a preservar as Forças Armadas brasileiras de um julgamento mais rigoroso pela sociedade, também garantiu certa legitimidade institucional aos militares, colocado-os, nas palavras do ministro da Marinha do governo Sarney, Almirante Henrique Sabóia, como "fiadores daquele processo de evolução democrática que estava acontecendo" (Castro, D’Araújo, 2001)..$^{14}$

Num contexto "de confiança entre governantes e governados" de que desfrutava o presidente nos primeiros anos de seu governo e avalizado pelos militares, Sarney envia ao Congresso Nacional um pacote de medidas democráticas, como o restabelecimento da legislação que garantia a eleição direta para presidente da República, prefeitos das capitais e áreas de Segurança Nacional, liberalização das atividades sindicais, voto dos analfabetos e, inclusive, a liberdade de organização de partidos políticos que outrora estavam na clandestinidade, incluindo o PCB (Partido Comunista Brasileiro) e o PC do B (Partido Comunista do Brasil).

Sobre estas medidas governamentais, a documentação esguiana pontua na direção do projeto político do governo:

Parece-nos que a melhor solução [para o registro dos partidos] seria deixar ao TSE apenas um único veto, no caso dos partidos políticos que pregassem em seus programas a negação do regime democrático e a violência como forma de ação política partidária. Aos eleitores caberia aceitar ou rejeitar as propostas de agremiações (DOC. 22, p. 39, 1986).

Apesar deste apoio inicial ao projeto do governo, a instituição não perde de vista seu antigo inimigo interno e estabelece suas reservas em relação à democratização. A documentação analisada sinaliza para o fato da preocupação ainda existente no interior da ESG, no início do governo Sarney, da migração dos antigos "inimigos internos" (os terroristas, os subversivos, os guerrilheiros) para as agremiações da oposição. O raciocínio que podemos depreender 
da documentação é que se deve abrir o sistema político para aqueles que tenham como consenso na vida política os Objetivos Nacionais Permanentes (ONP) da ESG. Ou, como sintetizam alguns documentos por nós analisados, "pessoas que sejam comprometidas com os ideais de 64 ".

Esta preocupação faz sentido à medida que, no ano de 1985 , realizaram-se em todo o país eleições municipais, figurando para o ano seguinte a eleição dos novos governadores e de deputados constituintes, responsáveis pela elaboração da nova Carta Magna e conseqüentemente, pela elaboração do novo quadro institucional brasileiro, que, dentre outras coisas, definia o futuro das Forças Armadas. A ESG estava fechada com as posições dos militares a respeito dessas determinações constitucionais, e estes, com o governo.

O presidente Sarney, por sua vez, obteve enormes benefícios políticos com os militares, pois foi por eles auxiliado durante todo o seu período governamental. Em 1986, o governo lançou um programa de controle da inflação e mudança da moeda - o Plano Cruzado -, todavia, o fracasso desse plano e a fragilidade do apoio político da Aliança Democrática levaram o presidente a, cada vez mais, apoiarse nas Forças Armadas ao longo de seu governo, cristalizando uma configuração institucional que Przeworski (1984) chama de "democracia tutelada", ou seja, um regime no qual os militares se desvencilham do exercício direto do governo, mas o fazem em boa ordem e prontos para, a qualquer eventualidade, caírem sobre os cidadãos que ameacem seus valores e idéias.

Essa relação de tutela não só foi cristalizada pelos militares no plano objetivo (na Constituição de 1988), mas sustentada no plano subjetivo por seus diversos interlocutores autorizados, entre eles a ESG, nosso objeto de análise. ${ }^{15}$ 
A sustentação ideológica dos militares

De fato, no processo constituinte, as Forças Armadas, através dos seus interlocutores autorizados, realizaram um dos mais eficientes lobbies - senão o mais eficiente - para assegurar seus poderes tradicionais e seu "modelo de autonomia militar" no processo político, de maneira organizada, sistemática e antecedente. ${ }^{16}$ A lógica interna desse modelo define-se pelos seguintes elementos: a função interventora, a subordinação limitada ao chefe de Estado e a preservação dos ministérios militares (Oliveira, 1994, p 127). O modelo de autonomia militar se contrapõe ao que Oliveira (1994) chama de "modelo instrumental", sob o qual as Forças Armadas, em detrimento de seu auto-emprego, estariam subordinadas ao poder político das instituições civis. A polarização ocorre exatamente em torno desta questão conceitual em relação à destinação constitucional das Forças Armadas. Ou elas se constituem "sujeitos autônomos" no processo político, ou “instrumentos subordinados" aos civis.

O que os militares defendiam na Constituição eram os poderes tradicionalmente postos a respeito do papel das Forças Armadas em relação ao Estado e à sociedade, ou seja, à defesa externa do país (os inimigos externos) e à defesa interna (os inimigos internos), "dentro dos limites da lei”. O que esta expressão garantia era, de fato, um julgamento autônomo das Forças Armadas do que estava ou não estava "dentro dos limites da lei". A questão de fundo posta aí não é somente se as Forças Armadas devem ou não intervir internamente no país (segurança interna), mas em que condições e sob qual direção política: a dos militares ou a dos civis? Usando o conceito de Oliveira (1994), a direção desta defesa dos militares ia ao encontro do "modelo de autonomia militar", visando evitar a subordinação militar às instituições civis. Acompanhando este debate, a ESG colocou-se na defesa desse projeto de autonomia militar durante o processo constituinte. 
A propósito da importância da ESG neste processo, relatam os professores esguianos entrevistados:

A escola colaborou intensamente com o processo constituinte, inclusive naquela comissão de notáveis havia vários esguianos e, mais do que isso, essa contribuição passou para o projeto de Constituição e você vai ver que, no preâmbulo, como também nos conceitos básicos da Constituição de 1988, estão os conceitos da Escola, inclusive o famoso papel dos militares... "garantia da lei e da ordem", "defesa da pátria, do território e da integridade", etc. todas as funções das Forças Armadas que estão lá na Constituição são temas amplamente debatidos aqui na Escola. (Professor da ESG entrevistado em novembro de 2004, no Rio de Janeiro).

Saíam daqui equipes para discutir com os constituintes, então era sobrecarregado o pessoal civil. Pedro Figueiredo teve um papel importante... Miguel Reale... nós levamos a fina flor da intelectualidade civil nossa aqui para expor nossas idéias. Não houve problema, nós colocávamos nosso ponto de vista e eles tiravam as conclusões que eles queriam... muitas coisas das salvaguardas dos direitos democráticos foi colaboração do pensamento da escola. (Professor da ESG entrevistado em novembro/dezembro de 2004, no Rio de Janeiro).

Como vemos, a ESG já vinha discutindo o papel das Forças Armadas na sociedade ao longo do governo Sarney, intensificando estas discussões com o corpo de seus estagiários, durante o processo constituinte de 1988. À produção simbólica interna da ESG, somaram-se as lutas objetivas dos militares, fundamentais para compreendermos os processos políticos em curso. Nesse processo político, os estagiários cumpriam um papel importante e na verdade, eram provenientes dos estratos superiores do Estado brasileiro - oficiais superiores/generais, professores, juristas, secretários de Estado - constituindo-se importantes quadros inseridos nas lutas políticas intra-estatais, objetivas e simbólicas. 
Este fato aqui é particularmente importante, qual seja a impregnação do caráter ideológico da DSN, justamente pela "qualidade destes estagiários". Pois, observamos que seu alunado provém da estrutura estatal, em sua imensa maioria de suas instâncias superiores (Tabela 1). Eles são provenientes dos ministérios civis, tribunais, ministérios militares, governos estaduais e municipais e universidades públicas. Da estrutura societal, são parcos. ${ }^{17} \mathrm{Em}$ números absolutos, de um total de 2.271 estagiários do período, 1.835 são provenientes do Estado e apenas 154 estagiários da chamada sociedade. Em termos percentuais, teríamos o equivalente a $80 \%$ de estagiários procedentes da estrutura estatal (não considerando os $13 \%$ dos dados não informados) contra $7 \%$ da estrutura societal. ${ }^{18}$

\section{Tabela 1 - Procedência dos Estagiários da ESG - 1974/1989}

\begin{tabular}{l|c|r|c}
\hline \multicolumn{1}{c|}{ Procedência } & Freq & \multicolumn{1}{c|}{$\%$} & Estrutura \\
\hline $\begin{array}{l}\text { Ministérios civis / tribunais } \\
\text { civis/ secretarias }\end{array}$ & 799 & $35 \%$ & Estatal \\
Ministérios militares/Emfa/ & 576 & $25 \%$ & \\
Tribunais militares & 282 & $12,5 \%$ & \\
Dados não informados e outros & 235 & $10,5 \%$ & \\
Governos estaduais/municipal/ & & $10 \%$ & \\
parlamento & 225 & & \\
Universidades & 120 & $5 \%$ & Societal \\
\hline Associação de classes/ & 34 & $2 \%$ & \\
empresários/ligas & $\mathbf{2 . 2 7 1}$ & $\mathbf{1 0 0 \%}$ & \\
Avulsos & & & \\
\hline Total &
\end{tabular}

Fonte: Almanaque Adesg-RS. Elaboração do autor. 


\section{Análise dos "objetos de atitude" na produção documental de estagiários da ESG}

"Objetos de atitude" são os objetos sobre os quais recai a avaliação, como pessoas, grupos, idéias, coisas, acontecimentos, já "termos avaliativos" são os termos que qualificam os objetos de atitude, digamos, os predicados (Bardin, 1977, p. 157), e "uma atitude é uma pré-disposição, relativamente estável (nível verbal), ou atos (nível comportamental) em presença de objetos (pessoas, idéias, acontecimentos, coisas, etc) de maneira determinada" (p.155).

Operando uma incursão quantitativa na produção dos estagiários ao longo do primeiro governo civil depois do regime autoritário, podemos melhor compreender como foram elaboradas as estratégias ideológicas, observando como a DSN é materializada pelos estagiários em seus trabalhos. Essas assimetrias sustentam os militares em uma relação de tutela. Esta relação pode ser ilustrada de maneira mais nítida nos Quadros 1 e 2.

Forças Armadas/Militares é um objeto de atitude sempre correlacionado a "defensores da lei e da ordem", "guardiãs da democracia", "intervêm nos momentos de crise". Sempre postos numa direção positiva, estando ausente a negatividade e a neutralidade. Diga-se de passagem, que, todos os trabalhos na ESG avaliam a instituição militar de forma positiva, enaltecendo o papel das Forças Armadas (Quadro 1). 


\section{Quadro 1 - Forças Armadas/Militares - correlação e direção}

\begin{tabular}{|l|c|c|}
\hline \multicolumn{1}{|c|}{ Positivo } & Neutro & Negativo \\
\hline Defensores da Lei e da Ordem, da Pátria (2) & $\mathrm{NE}$ & $\mathrm{NE}$ \\
Guardiãs da Democracia (2) & $\mathrm{NE}$ & $\mathrm{NE}$ \\
Intervém nos momentos de crise (2) & $\mathrm{NE}$ & $\mathrm{NE}$ \\
Intervém na falência do poder nacional (2) & $\mathrm{NE}$ & $\mathrm{NE}$ \\
Atendem ao clamor Popular (2) & $\mathrm{NE}$ & $\mathrm{NE}$ \\
Defesa Interna (2) & $\mathrm{NE}$ & $\mathrm{NE}$ \\
Defesa externa (2) & $\mathrm{NE}$ & $\mathrm{NE}$ \\
Defesa do Estado (1) & $\mathrm{NE}$ & $\mathrm{NE}$ \\
Permanentes, nacionais, hierárquicas e \\
disciplinadas (1) & $\mathrm{NE}$ & $\mathrm{NE}$ \\
Dedicadas, despreendidas, abnegadas (1) & $\mathrm{NE}$ & $\mathrm{NE}$ \\
Permanentemente preparadas (1) & $\mathrm{NE}$ & $\mathrm{NE}$ \\
Canal de mobilidade social, congregadoras de & & \\
etnias, culturas e correntes sociais (1) & $\mathrm{NE}$ & $\mathrm{NE}$ \\
\hline
\end{tabular}

$\mathrm{NE}=$ não encontrado

Fonte: Trabalhos Especiais (TE) 1974-1989. Quadro do autor.

(1) apenas uma menção a estes objetos.

(2) duas ou mais menções aos "objetos de atitude", pois nosso recorte amostral do conteúdo dos trabalhos ficou reduzido diante do volume da documentação total consultada ao longo de 15 anos de história da ESG.

Sociedade/Nação/Povo, aparece associado a dois campos polares.20 No campo positivo, há uma enaltação desta nação, então ela é "democrática", "criativa", "miscigenada", mas, no campo negativo, ela "deve amadurecer", "não conhece seus representantes", é "presa fácil" (Quadro 2). 


\section{Quadro 2 - Sociedade/Nação/Povo - correlação e direção}

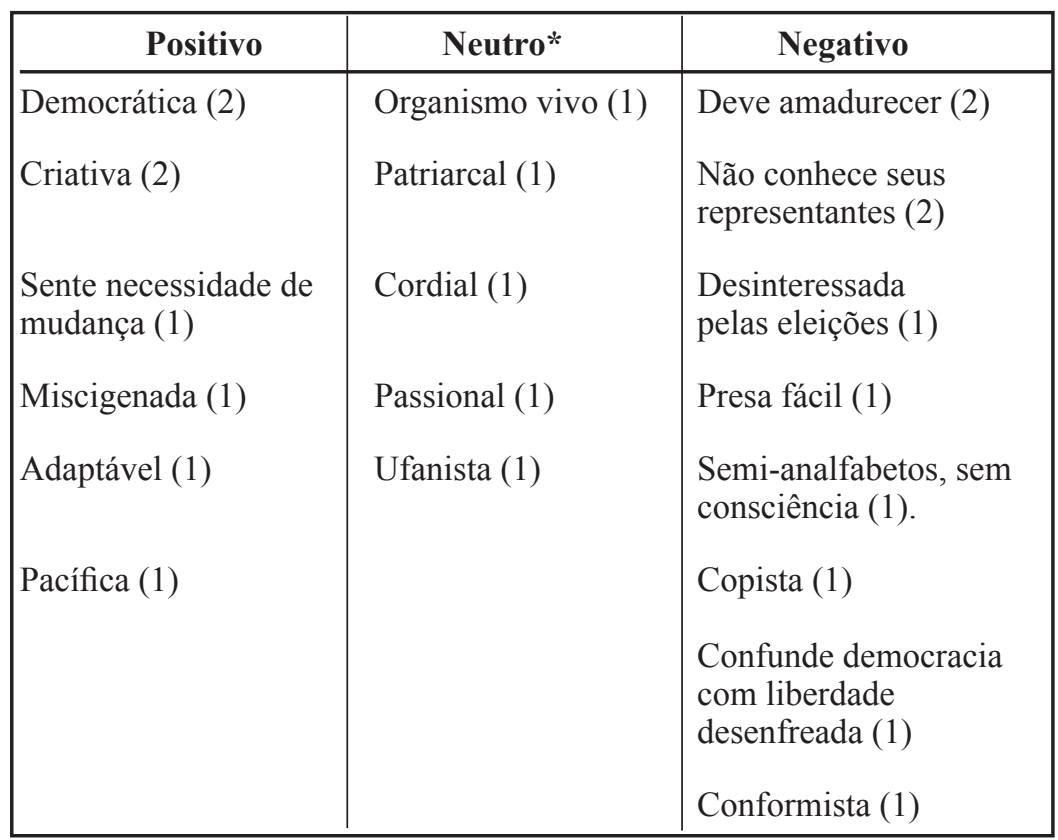

Fonte: Trabalhos Especiais (TE) 1974-1989/quadro do autor.

* Os atributos neutros são aqueles que, uma vez encontrados nos textos não indicavam uma posição de negatividade ou positividade de sua colocação. Por exemplo a palavra "cordial" apareceu referindo-se à obra de Sérgio Buarque de Holanda, apenas como um juízo de fato, não um juízo de valor.

(1) apenas uma menção a estes objetos.

(2) duas ou mais menções aos "objetos de atitude", pois nosso recorte amostral do conteúdo dos trabalhos ficou reduzido diante do volume da documentação total consultada ao longo de 15 anos de história da ESG.

É exatamente nesta brecha que entram os militares. Estas defecções da sociedade colocam-na num risco permanente, que, a curto prazo, não sendo passíveis de serem sanadas, encontram nos militares seus protetores tradicionais e legais. $\mathrm{O}$ espaço aberto pelos atributos negativos à sociedade justifica a intervenção dos militares, que só possuem atributos positivos. Depreende-se, da relação destes quadros, a idéia de Forças Armadas fortes, Sociedade fraca; Forças 
Armadas ordem, Sociedade desordem. Como escrevemos em outros trabalhos, a anterioridadedoEstadoe, conseqüentemente, dosmilitares em relação à sociedade ajudam a explicar este tipo de postura militar que se arroga a tutela da sociedade (Santos, 2005, especialmente capítulo 2).

\section{Conclusão}

Procuramos demonstrar que a ESG cumpriu um papel importante no processo de transição para a democracia no Brasil (1974/1989) justamente por seu caráter ideológico, qual seja, o de sustentar no plano simbólico a manutenção de relações assimétricas de poder entre civis e militares dentro do aparelho de Estado, recrutando para isso parte da elite civil/militar brasileira. Neste sentido, nossa análise formal das construções simbólicas na ESG colados no contexto sócio-histórico do período com o uso da Hermenêutica de Profundidade (HP) e análise de conteúdo de Bardin (1977) nos permitiram duas conclusões basilares.

Primeiramente, as produções simbólicas durante os dois últimos governos militares demonstraram uma congruência com as ações do governo. Em outras palavras, a busca pela institucionalização do Estado de Segurança, através da edificação de instituições que garantiam o grupo de poder no Estado, levadas a cabo por Geisel e Figueiredo, recebe o respaldo da Escola. Assim, a mobilização dos sentidos vai ao encontro das relações de poder assimétricas edificadas pelo regime autoritário. Esta mobilização pode ser constatada pelos modos de operação da ideologia identificados na documentação analisada - os modos de legitimação, dissimulação, e fragmentação - assim como pelas respectivas estratégias racionalização, universalização, eufemização, eternalização etc. -, que procuravam sustentar os militares enquanto governo no poder e, conseqüentemente, o próprio regime. 
Em segundo lugar, na busca pela institucionalização do Estado de Segurança Nacional estava embutida a alocação das Forças Armadas num papel tutelar em relação à sociedade. O que é corroborado pelos documentos analisados, nos quais é garantido que "os militares enquanto instituição" saíssem fortalecidos deste processo. Inclusive a passagem dos governos militares para os civis se dá com garantias constitucionais para os primeiros, assegurando a democracia tutelar.

Assim, tanto a manutenção do governo, quanto a manutenção das Forças Armadas em seu papel tutelado, no período em análise, foram justificadas e legitimadas na ESG, configurando assim esta instituição como um lócus ideológico de sustentação do regime autoritário/tutelar durante o processo transicional da política brasileira. Aqui também a mobilização simbólica no período foi ao encontro destas relações de dominação civil/militares.

Em outras palavras, procuramos deixar claro, através da análise da produção simbólica dos estagiários da ESG, como se deu a sustentação ideológica das relações de dominação assimétricas entre civil-militares, bem como, conseqüentemente, a eficiência da DSN sobre os estagiários esguianos.

\section{Notas}

1 Estes trabalhos, buscando os "links" existentes entre a instituição e a política nacional, tornaram-se imprescindíveis a este estudo, pois, a partir de suas contribuições teóricas e metodológicas, tornou-se possível construirmos nosso objeto de investigação.

2 Foram consultados quase dois mil documentos disponíveis na ESG referentes aos anos de 1974 a 1989. Dado o volume de informações, analisamos uma amostra dessa documentação, utilizando a técnica da análise de conteúdo temático, a partir da categorização dos trabalhos encontrados em temas políticos e militares (selecionamos os trabalhos 
no limite da saturação amostral). Priorizamos os TE (trabalhos de estagiários de final de curso) e a publicação da Revista da Escola Superior de Guerra do período, bem como entrevistas com o corpo de professores da instituição..

3 Segundo Stepan (1986), "os militares enquanto governo" constituemse das lideranças que dirigem o governo da pólis. De maneira geral, é composto pelo general-presidente e seus principais assessores, alguns dos quais podem ser civis. Já "os militares enquanto instituição" são o grosso da corporação militar, que estrutura suas bases e administra os ciclos de treinamento de rotina, que gerencia a complexa rede do sistema militar de ensino, que organiza a burocracia militar.

4 Para uma discussão mais detalhada das críticas de Coelho (1985) às concepções de Stepan (1971), ver Coelho (1990). Ver também Stepan (1986), onde o autor também utiliza este conceito nesta mesma direção, mostrando como a ESG vê o processo de transição no Brasil.

5 Muito embora advirta que não está preocupado se o pensamento geopolítico da escola possa ser ou não ideológico.

6 Há uma diferença nas concepções de Marx e Gramsci em relação ao conceito de ideologia, que não estamos desconsiderando, enquanto Marx a concebe como algo pejorativo pertencente a uma classe, Gramsci a vê, ora como "ideologia historicamente orgânica", acima de interesses particularistas e congregadora de consensos históricos necessários, ora como "ideologia parcial, falsa" que substancia uma cultura burguesa hegemônica num determinado bloco histórico que precisa ser superada pelas classes subalternas. Não entrando na querela destas discussões, pois não é nosso objeto discutir o conceito em si, mas o uso deste pelos autores citados, entendemos neste trabalho que os estudos que se apropriaram dos fundamentos gramscianos tenderam a utilizar a ideologia nesta segunda concepção, parcial e falsa, daí os localizarmos nos "negativos".

7 Estabelecer significa, segundo Thompson (1995), que o sentido pode criar e instituir relações de dominação e sustentá-las, quer dizer que o sentido pode servir para manter e reproduzir relações de dominação 
por meio de um processo contínuo de produção e recepção de formas simbólicas.

8 Como argumento Bourdieu (2000, p. 152), "os que ocupam as posições dominadas no espaço social estão também em posições dominadas no campo de produção simbólica".

9 Como argumenta também Rezende (2001), inspirada em Gramsci e Mannheim, não há possibilidade de separarmos as condições objetivas das subjetivas, ou, em outras palavras, os interesses dos valores. A vida social só se torna inteligível quando somos capazes de entender esta conexão.

10 Como podemos deduzir em Dahl (1976), as pessoas buscam o poder mais por defesa de seus próprios interesses do que por defesa do bem comum.

111 Na Constituição de 1967 encontramos as Forças Armadas, constituídas pela Marinha de Guerra, Exército e Aeronáutica, como instituições nacionais, permanentes e regulares, organizadas com base na hierarquia e disciplina, sob a autoridade suprema do presidente da República e dentro dos limites da lei. Destinando-se, por seu turno, às Forças Armadas a defender a Pátria e garantir os poderes constituídos, a lei e a ordem. (Constituição Federal de 1967, artigo 92).

12 Num sentido rousseauniano, seria recuperar a dependência das coisas, das leis, não de pessoas particulares.

13 Inclusive, Sabóia foi aluno da ESG na turma de 1974.

14 Sobre a discussão do "poder e influência" dos militares nos pós-regimes autoritários, a bibliografia bifurca-se em Hunter (1997), na defesa da perda de influência dos militares na política, e Zaverucha (2000), na tese contrária, das "prerrogativas militares".

15 A subcomissão de Defesa do Estado organizou oito sessões públicas com uma agenda desequilibrada de convidados. Dos 28 convidados, somente três apresentaram sugestões contrárias ao status quo, acerca das relações entre civis e militares. (Zaverucha, 1994). 
16 Conforme assinalou acertadamente Gaspari (2003, p. 122) referindose à ESG, o “(...) número de estagiários sem ligação com o Estado dificilmente alcançava um terço das turmas". Não chega a $10 \%$ das turmas em média do período, conforme critérios de nossa análise.

17 A maioria dos professores universitário convidados pela ESG provém de instituições públicas federais, daí os colocarmos como parte da estrutura estatal.

Ideology and domination in Brazil (1974-1989): a study about the Superior School of War

Abstract: This work analyzes the forms of symbol production adopted by Escola Superior de Guerra ESG (Superior School of War) and their relation to the asymmetrical dominance relationship between civilians and the military in Brazil. The hypothesis guiding this work is that ESG constitutes a locus of production and receiving of ideology-related symbolic forms, according to Thompson (1995). In other words, the meanings mobilized by this institution in the period under analysis, during the transition towards democracy in Brazil (1974/1989) acted, under those specific social and historical circumstances, to sustain long-lasting asymmetrical dominance relationships between civilians and the military, thus crystallizing its ideological nature. So, we used of theoretical and methodological proposal of Thompson (1995) in his Depth Hermeneutics (HP) and Bardin's content analysis.

Key words: ideology, domination, Superior School of War.

\section{Referências bibliográficas}

ADERALDO, Vanda Maria Costa. A escola superior de guerra: um estudo de currículos e programas. Dissertação (Mestrado) - IUPERJ, Rio de Janeiro, 1978.

ALVES, M. H. Estado e oposição no Brasil (1964-1984). Petrópolis: Vozes, 1984. 
BARDIN, L. Análise de conteúdo. Lisboa: Ed. 70, 1977.

BOURDIEU, P. O Poder simbólico. Rio de Janeiro: Bertrand Brasil, 2000.

CASTRO, C.; D’ARAÚJO, M. C. Militares e politica na Nova República. Rio de Janeiro: FGV, 2001.

COELHO, Edmundo Campos. A instituição militar no Brasil: um ensaio bibliográfico. In: BIB, ANPOCS. Rio de Janeiro, n. 15 a 19, p. 335$359,1990$.

D'ARAÚJO, Maria Celina; CASTRO, Celso (org.). Democracia e forças armadas no Cone Sul. Rio de Janeiro: FGV, 2000.

DAHL, R. A Moderna análise política. Rio de Janeiro: Forense, 1976.

DREIFUSS, René Armand. A conquista do Estado: ação Política, poder e golpe de classes. 3 ed. Petrópolis: Vozes, 1981.

GASPARI, E. A ditadura derrotada. São Paulo: Companhia das Letras, 2003.

HUNTER, Wendy. Eroding military influence in Brazil: politicians against soldier. Cape Hill: University of North Carolina, 1997.

IANNI, Otávio. O ciclo da revolução burguesa. Petrópolis: Vozes, 1985.

MIYAMOTO, Shiguenoli. Geopolitica e poder no Brasil. Campinas: Papirus, 1995.

O'DONNELL, G; SCHMITTER, P. C. Autoritarismo e democratização. São Paulo: Vértice, 1986.

OLIVEIRA, Eliézer Rizzo de. As forças armadas: política e ideologia no Brasil (1964-1969). Petrópolis: Vozes, 1976.

. De Geisel a Collor: forças armadas, transição e democracia. Campinas: Papirus, 1994.

OLIVEIRA, Eliezer R. (Org). Militares: pensamento e ação. Campinas: Papirus, 1987. 
PRZEWORSKI, A. Amas a incerteza e serás democrático. Novos Estudos, n. 9, p. 36-46, 1984.

REZENDE, M. J. de. A ditadura militar no Brasil: repressão e pretensão de legitimidade e 1964-1984. Londrina: UEL, 2001.

SANTOS, Everton Rodrigues. A revitalização do uso conceitual da ideologia nos estudos militares: um aplicativo à Escola Superior de Guerra. Revista Gestão e Desenvolvimento, Feevale, v. 3, n.1, jan. 2006.

. Ideologia e dominação no quadro da transição democrática no Brasil (1974/1989): um estudo sobre a Escola Superior de Guerra. Porto Alegre. Tese (Doutorado) - UFRGS, 2005.

. Um olhar esguiano da abertura. In: TESKE, Ottmar (org). Sociologia textos e contextos. Canoas: ULBRA, 2005. p. 219/249.

SILVA, G. C. A conjuntura política nacional: o poder executivo. Revista da Escola Superior de Guerra, v. 5, n. 12, p. 111-135, 1989.

STEPAN, Alfred. Brasil: los militares y la política. Buenos Aires: Amorrortu, 1971.

. Os militares: da abertura à Nova República. 3. ed. Petrópolis (RJ): Vozes, 1986.

THOMPSON, J. B. Ideologia e cultura moderna. Petrópolis (RJ): Vozes, 1995.

VINCENT, Andrew. Ideologias políticas modernas. Rio de Janeiro: Jorge Zahar, 1992.

WEBER, Marx. Economia e sociedade. Brasília (DF): UNB, 1999. v. 2.

ZAVERUCHA, J. Frágil Democracia. Rio de Janeiro: Civilização Brasileira, 2000.

. Rumor de sabres: tutela Militar ou Controle Civil. São Paulo: Ática, 1994. 